\title{
Knowledge, attitude and practice of foot care in diabetes patients with foot at risk attending diabetology department of a tertiary care hospital
}

\author{
Sruthy Sivan ${ }^{1 *}$, Sruthi Prasad ${ }^{1}$, Parvathy Nandan ${ }^{1}$, Haritha K. Harikumar ${ }^{1}$, \\ Lallu Mariam Jacob ${ }^{1}$, Thankam D. ${ }^{2}$
}

\author{
${ }^{1}$ Department of Pharmacy Practice, The Dale View College of Pharmacy and Research Centre, Thiruvananthapuram, \\ Kerala, India \\ ${ }^{2}$ Department of Diabetology, SK Hospital, Thiruvananthapuram, Kerala, India
}

Received: 10 October 2020

Revised: 06 January 2021

Accepted: 07 January 2021

\section{*Correspondence:}

Dr. Sruthy Sivan,

Email: sruthys1919@gmail.com

Copyright: (C) the author(s), publisher and licensee Medip Academy. This is an open-access article distributed under the terms of the Creative Commons Attribution Non-Commercial License, which permits unrestricted non-commercial use, distribution, and reproduction in any medium, provided the original work is properly cited.

\section{ABSTRACT}

Background: The current study was undertaken to assess the knowledge, attitude and practice (KAP) of foot care among diabetes patients with foot at risk, to evaluate the impact of counselling in terms of KAP score, VPT (vibration perception threshold) value, foot examination status and other clinical parameter, to assess the severity of peripheral neuropathy in diabetes patients based on VPT value and to assess the prevalence of peripheral neuropathy among men and women.

Methods: A prospective cross-sectional and interventional study was conducted in the diabetology department of a tertiary care hospital in South India. A total of 100 diabetes patients with foot at risk were selected for the study. A questionnaire was used to assess the knowledge, attitude and practice of foot care among diabetes patients with foot at risk. The questionnaire consists of total 24 questions. Their knowledge, attitude and practice were classified as good, satisfactory and poor depending upon the score. For the KAP, if score is $\geq 70 \%$ it was regarded as good, $50-69 \%$ as satisfactory and $<50 \%$ as poor.

Results: The study assessed that among 100 patients, $6 \%$ of the participants had good knowledge before counselling and after counselling, $46 \%$ had satisfactory level of knowledge and $43 \%$ had good knowledge. Most of the patients had a good attitude towards foot care before and after counselling. Only $1 \%$ of patients were in good practice before counselling and after counselling $62 \%$ of the patients had satisfactory practice and $25 \%$ had good practice. The study revealed that about $53 \%$ had a VPT value of $26-50 \mathrm{~V}$ before providing counselling and after counselling about $43 \%$ of the participants VPT became 26-50 V. The study also showed that the prevalence of peripheral neuropathy according to VPT value is more in males than females.

Conclusions: Poor knowledge and poor practice were observed among the diabetes patients with foot at risk who had attended the diabetology department. Poor knowledge and practice are the major reason for the amputation of limb as the people are unaware of their foot care. Thus, by providing proper education regarding foot care, the foot complications can be improved and there by the amputation rate can be reduced to an extent.

Keywords: Diabetes mellitus, Diabetic foot, KAP, Peripheral neuropathy

\section{INTRODUCTION}

Diabetes mellitus is a chronic disease caused by inherited and/or acquired deficiency in production of insulin by the pancreas, or by the ineffectiveness of the insulin produced. Such a deficiency results in increased concentrations of glucose in the blood, which in turn damage many of the body's systems, in particular the blood vessels and nerves. ${ }^{1}$ 
According to WHO, about 425 million adults (20-79 years) were affected with diabetes worldwide. It is estimated that, by 2045 it will rise to 609 million. India ranks second in the World with nearly 8 million diabetes patients with a prevalence rate of $10.4 \% .^{2}$

On long term, diabetes may lead to various complications. The microvascular complications include retinopathy, nephropathy and neuropathy and the macrovascular complications includes stroke, peripheral vascular disease and myocardial infarction. ${ }^{3,4}$

Diabetic foot is one of the most significant and devastating complications of diabetes. World health organization describes diabetic foot as, " The foot of a diabetic patient that has the potential risk of pathologic consequences, including infection, ulceration, and/or destruction of deep tissues associated with neurologic abnormalities, various degrees of peripheral vascular disease, and/or metabolic complications of diabetes in the lower limb."

The diabetic foot is characterized by a classical triad of neuropathy, ischemia and infection. Almost $85 \%$ of amputations are preceded by a foot ulcer. The main reasons for the development of these ulcers are peripheral neuropathy, foot deformities, minor foot trauma and peripheral artery diseases..$^{5,6}$

\section{Staging of diabetic foot}

Normal foot: The foot is normal and not at risk, no risk factors (neuropathy, ischemia, deformity, callus and edema.

High risk foot: One or more risk factors for foot ulceration.

Foot with ulcer: Ulceration in the neuropathic foot develops at the sites of high mechanical pressure on the plantar surface. Ulcers in foot with neuropathy and ischemia (neuro-ischemic foot) occur on the margins of the foot and toes, at sites of prolonged low pressure.

Foot with cellulitis: Ulcers with presence of cellulitis.

Foot with necrosis: Neuropathic foot: infection is the usual cause of necrosis.

Neuro-ischemic foot: infection is the most common reason, although severe ischemia can directly lead to necrosis.

Unsalvageable foot presentation: The foot cannot be saved and will need a major amputation.

In this study foot at risk were assessed by foot examination status and by using vibration perception threshold (VPT)

\section{Vibration perception threshold (VPT)}

Biothesiometer can be used to quantify the degree of neuropathy. With the patient lying supine, the stylus of the instrument is placed at five different locations on the feet (distal plantar surface of great toe, proximal plantar surface of great toe, lateral surface of great toe, plantar surface of digit-minimi and plantar surface of calcaneus) of both the legs to sense the vibration. The amplitude is then slowly increased at a rate of $1 \mathrm{mV} / \mathrm{s}$ until the patient can feel the vibration sensation. The voltage at which patient first felt the vibration sensation is called vibration perception threshold (VPT). A VPT more than $25 \mathrm{~V}$ is considered abnormal and has been shown to be strongly predictive of subsequent foot ulceration. The risk of ulceration is increased to 4-fold if VPT is $25-33 \mathrm{~V}$ and is increased to 20 fold once VPT exceeds $42 \mathrm{~V} .{ }^{5,8,9}$

In Kerala, although most of the patients are highly literate, many of them are unaware of their disease condition and the life style modification, which in turn is the major reason of morbidity and hospitalization among such patients. Therefore, a study gauging the level of KAP of foot care with foot at risk patients is necessary to improve the patient well-being and welfare.

Most amputation in patients with diabetes are preceded by a foot ulcer, whose risk factors are barefoot walking, inappropriate foot ware, poor foot hygiene and delay in seeking medical attention. Proper guidance and education regarding foot care practice can make significant improvements in diabetic foot. The number of patients getting amputed is increasing day by day which is preventable by effective identification, education and preventive foot care practice. Therefore, lifestyle modification remains a cornerstone of management.

The current study attempts to evaluate the knowledge, attitude and practice of foot care in patients with foot at risk. The result point towards an improvement in knowledge, attitude and practice to those who were counselled and made aware of the importance of foot care practice. Educating patients is likely to be effective if we are aware of their current knowledge, attitude and practices on foot care.

\section{Objectives}

Primary objective: To assess the KAP regarding foot care among diabetes patients with foot at risk. To evaluate the impact of counseling in terms of KAP score, VPT value, foot examination status and other clinical parameter status.

Secondary objectives: To assess the severity of peripheral neuropathy in diabetes patients based on VPT value. To assess the prevalence of peripheral neuropathy among men and women.

\section{METHODS}

\section{Study design}

Cross sectional study design and non-randomised study design were used as a study design for current study. 


\section{Study setting}

Study setting included diabetology department of a 300 bedded tertiary care teaching hospital.

\section{Study duration}

The duration of the study carried out from September 2018 to February 2019.

\section{Study participants}

The participants included in the study had diabetes with foot at risk.

\section{Study materials}

The material required for the study were informed consent form, patient data collection form, KAP questionnaire, infographics and diabetes foot care kit.

\section{Study subjects}

Study subjects involving in the study were 100 .

\section{Inclusion criteria}

Inclusion criteria included all patients above 30 years of age who are diagnosed with type $2 \mathrm{DM}$ for more than 5 years were included in the study.

\section{Exclusion criteria}

Exclusion criteria excluded the paediatric patients, pregnant and nursing mothers, patients unable to communicate verbally, newly diagnosed DM patients, patients with amputated foot and the patients who denied consent to be part of the study were excluded from the study.

A pilot study was conducted in 10 patients to assess whether the prepared questionnaire is efficient for the patient or not. From the pilot study we found that $50 \%$ had knowledge about foot care. Based on this information sample size were calculated.

Sample size, $n=z^{2} p_{\alpha}(100-p) / d^{2}$

About 300 patients visited the OP in diabetology department during the study period from September 2018 to February 2019. The patients were scrutinized based on the inclusion criteria. They were informed about the study and each of them signed the informed consent before enrolling in the study. Patients data were transcribed on a data form comprising of demographic details, family history, social history and duration of diabetes. Patients were interviewed to assess their knowledge, attitude and practice regarding foot care using a questionnaire. The questionnaire consists of total 24 questions; 8 questions for knowledge, 7 questions for attitude and 9 questions for the practice of foot care. After obtaining the consent, counselling was given to the patients regarding diabetic foot care using an infographics and a diabetic foot care kit. These patients during their next visit were reviewed using the same questionnaires to assess their improvement. The score for knowledge, attitude and practice was determined for each subject. Their knowledge, attitude and current practice of foot care were classified as good, satisfactory and poor depending upon the score obtained. For the knowledge, if the score was $\geq 70 \%$ (6-8) it was regarded as good, score of $50-69 \%$ (4-5) was regarded as satisfactory and that less than $50 \%(<4)$ was regarded as poor. For the attitude, if score was $\geq 70 \%$ (5-7), it was regarded as good, score of 50-69\% (3-4) was regarded as satisfactory and that less than $50 \%(<3)$ was regarded as poor. For the practice, if score was $\geq 70 \%$ (7-9), it was regarded as good, score of 50-69\% (4-6) was regarded as satisfactory and anything less than $50 \% \quad(<4)$ was regarded as poor.

Above classification was made by using the score used by Desalu et al in their study. ${ }^{10}$

Data collected were analyzed using statistical package for the social sciences, version 22 (SPSS). Mean, median, SD were obtained from descriptive statistics. The impact of patient counselling in terms of KAP score and the VPT value assessed before and after counselling were determined by Wilcoxon signed rank test. The foot examination status and other clinical parameters before and after counselling were compared with McNemar's test.

\section{RESULTS}

Table 2, showed that out of 100 patients, $57 \%$ were males and $43 \%$ were females and $45 \%$ of the patients were in the age range $60-69$ years. $64 \%$ had a positive family history of DM and 51\% had diabetes for 11-20 years.

From the above table (Table 5) it has been found that there was a statistically significant improvement in the KAP Score after counselling, showing that the counselling was very effective in improving the KAP Score.

From the above table (Table 6 ) it has been found that there was a statistically significant reduction in the median value of VPT after counselling, showing that the counselling was very effective in reducing the VPT value.

From the above table (Table 7) it has been found that there was a significant improvement in foot examination status after counselling.

From the above table (Table 8 ) it has been found that there was a significant improvement in the investigational parameter status after counselling. 
Table 1: KAP questionnaire.

\begin{tabular}{|c|c|}
\hline $\begin{array}{l}\text { S. } \\
\text { No. }\end{array}$ & KAP Questionnaire \\
\hline A & Knowledge related questions \\
\hline 1 & $\begin{array}{l}\text { Are you aware that smoking can reduce blood } \\
\text { supply to the foot? }\end{array}$ \\
\hline 2 & $\begin{array}{l}\text { Are you aware that you should not wear Hawaii } \\
\text { slipper? }\end{array}$ \\
\hline 3 & $\begin{array}{l}\text { Do you know what all diagnostic procedure has } \\
\text { to be done? }\end{array}$ \\
\hline 4 & Is there any sore area or warts under your foot? \\
\hline 5 & $\begin{array}{l}\text { Have you experienced bleeding or pus from } \\
\text { your feet? }\end{array}$ \\
\hline 6 & $\begin{array}{l}\text { Do you think of getting wound due to the loss } \\
\text { of foot sensation? }\end{array}$ \\
\hline 7 & $\begin{array}{l}\text { Are you aware of cutting nails properly- (A) } \\
\text { Using nail cutter/nail file, (B) Blade? }\end{array}$ \\
\hline 8 & $\begin{array}{l}\text { Did you feel any symptoms such as tingling } \\
\text { sensation, numbness, wasting of muscle, } \\
\text { heaviness, ache, difficulty to walk? }\end{array}$ \\
\hline $\mathbf{B}$ & Attitude related questions question \\
\hline 1 & $\begin{array}{l}\text { Are you ready to change your diet and exercise } \\
\text { pattern to reduce the risk of diabetes? }\end{array}$ \\
\hline 2 & $\begin{array}{l}\text { Are you willing to check your foot daily and } \\
\text { change your foot wear as said by doctor? }\end{array}$ \\
\hline 3 & $\begin{array}{l}\text { Do you wear your foot wears indoor and } \\
\text { outdoor as said by the doctor? }\end{array}$ \\
\hline 4 & $\begin{array}{l}\text { Do you think that you are capable of leading a } \\
\text { normal life, if you are ready to take measures } \\
\text { against diabetes? }\end{array}$ \\
\hline 5 & Do you take your anti diabetic drug regularly? \\
\hline 6 & Do you dry your feet with cloth, after washing? \\
\hline 7 & $\begin{array}{l}\text { What would you do if you saw any changes in } \\
\text { your feet- Will you take care of yourself? } \\
\text { Will you consult your Doctor? }\end{array}$ \\
\hline $\mathbf{C}$ & Practice related questions \\
\hline 1 & Do you wash your feet daily? \\
\hline 2 & $\begin{array}{l}\text { Do you apply moisturizing cream for dryness of } \\
\text { your feet? }\end{array}$ \\
\hline 3 & Do you use mirror to check your sole of feet? \\
\hline 4 & $\begin{array}{l}\text { Do you check the temperature of water before } \\
\text { dipping your foot? }\end{array}$ \\
\hline 5 & Do you put powder in between your toes? \\
\hline 6 & $\begin{array}{l}\text { Do you check your foot wear before wearing } \\
\text { for any nail or stone? }\end{array}$ \\
\hline 7 & Do you buy foot wears in the evening? \\
\hline 8 & Do you keep hot water bags on your foot? \\
\hline 9 & Do you wear tight socks? \\
\hline
\end{tabular}

Table 2: Demographic details of the patients.

\begin{tabular}{|lll|}
\hline Variables & Number & Percentage $(\%)$ \\
\hline Gender & & \\
\hline Male & 57 & 57.0 \\
\hline Female & 43 & 43.0 \\
\hline Age range (year) & & \\
\hline $30-39$ & 1 & 1.0 \\
\hline $40-49$ & 8 & 8.0 \\
\hline $50-59$ & 23 & 23.0 \\
\hline $60-69$ & 45 & 45.0 \\
\hline $70-79$ & 18 & 18.0 \\
\hline $80-89$ & 5 & 5.0 \\
\hline Family history & & \\
\hline Yes & 64 & 64.0 \\
\hline No & 36 & 36.0 \\
\hline Duration of diabetes & \\
\hline$\leq 10$ & 35 & 35.0 \\
\hline $11-20$ & 51 & 51.0 \\
\hline $21-30$ & 11 & 11.0 \\
\hline $31-40$ & 3 & 3.0 \\
\hline
\end{tabular}

Table 3: Distribution of patients based on VPT value before and after counselling.

\begin{tabular}{|lll|}
\hline VPT range & Before & After \\
\hline$\leq \mathbf{1 5}$ & 11.0 & 19.0 \\
\hline $\mathbf{1 6 - 2 5}$ & 36.0 & 38.0 \\
\hline $\mathbf{2 6 - 5 0}$ & 53.0 & 43.0 \\
\hline
\end{tabular}

Table 4: Distribution of patients based on knowledge score, attitude score and practice score before and after counselling.

\begin{tabular}{|lll|}
\hline $\begin{array}{l}\text { Variables } \\
\text { Knowledge score }\end{array}$ & Before & After \\
\hline Poor (<4) & 65.0 & 11.0 \\
\hline Satisfactory (4-5) & 29.0 & 46.0 \\
\hline Good (6-8) & 6.0 & 43.0 \\
\hline Attitude score & & \\
\hline Poor (<3) & 1.0 & 0 \\
\hline Satisfactory (3-4) & 28.0 & 2.0 \\
\hline Good (5-7) & 71.0 & 98.0 \\
\hline Practice score & & \\
\hline Poor (<4) & 87.0 & 13.0 \\
\hline Satisfactory (4-6) & 12.0 & 62.0 \\
\hline Good (7-9) & 1.0 & 25.0 \\
\hline
\end{tabular}

Table 5: Impact of counselling in terms of KAP score before and after counselling.

\begin{tabular}{|c|c|c|c|c|c|}
\hline Parameter & Mean & Median & SD & Test used & $\mathbf{P}$ \\
\hline \multicolumn{4}{|l|}{ Knowledge } & \multirow{6}{*}{$\begin{array}{l}\text { Wilcoxon signed } \\
\text { rank test }\end{array}$} & \multirow{6}{*}{$<0.0001 * *$} \\
\hline Before & 3.06 & 3 & 1.46 & & \\
\hline After & 5.12 & 5 & 1.15 & & \\
\hline \multicolumn{4}{|l|}{ Attitude } & & \\
\hline Before & 4.97 & 5 & 1.12 & & \\
\hline After & 6.79 & 7 & 0.56 & & \\
\hline
\end{tabular}

Continued. 


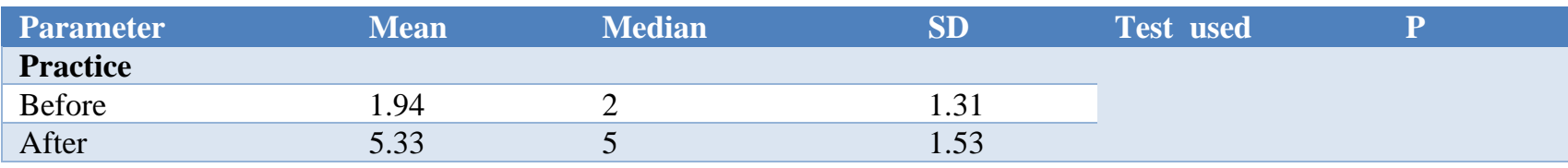

Table 6: Impact of counselling in terms of VPT value before and after counselling.

\begin{tabular}{|llllll|} 
Parameter & Mean & Median & SD & Test used & P value \\
\hline Before & 29.86 & 26.5 & 12.14 & Wilcoxon signed & $<0.0001^{* *}$ \\
\cline { 1 - 2 } & 26.52 & 22.5 & 11.68 & rank test & \\
\hline
\end{tabular}

Table 7: Impact of counselling in terms of foot examination status before and after counselling.

\begin{tabular}{|c|c|c|c|}
\hline Variables & Number & Test applied & P value \\
\hline Dry Skin & & \multirow{24}{*}{ McNemar's test } & \multirow{3}{*}{$0.008^{* *}$} \\
\hline Before & 92 & & \\
\hline After & 84 & & \\
\hline \multicolumn{2}{|l|}{ Fissures } & & \multirow{3}{*}{$<0.0001^{* *}$} \\
\hline Before & 63 & & \\
\hline After & 18 & & \\
\hline \multicolumn{2}{|l|}{ Swelling } & & \multirow{3}{*}{$<0.0001^{* *}$} \\
\hline Before & 53 & & \\
\hline After & 20 & & \\
\hline \multicolumn{2}{|l|}{ Callus } & & \multirow{3}{*}{$<0.0001^{* *}$} \\
\hline Before & 27 & & \\
\hline After & 11 & & \\
\hline \multicolumn{2}{|l|}{ Mycosis } & & \multirow{3}{*}{$0.002^{* *}$} \\
\hline Before & 18 & & \\
\hline After & 5 & & \\
\hline \multicolumn{2}{|l|}{ Nail } & & \multirow{3}{*}{0.375} \\
\hline Before & 49 & & \\
\hline After & 46 & & \\
\hline \multicolumn{2}{|l|}{ Hair } & & \multirow{3}{*}{1.00} \\
\hline Before & 42 & & \\
\hline After & 42 & & \\
\hline \multicolumn{2}{|l|}{ Gangrene } & & \multirow{3}{*}{0} \\
\hline Before & 0 & & \\
\hline After & 0 & & \\
\hline
\end{tabular}

Table 8: Investigation parameter status before and after counselling.

\begin{tabular}{|lllll|}
\hline Status & Before & After & Test applied & \multicolumn{2}{c}{ P value } \\
\hline Vibration & 28 & 38 & & $0.006^{* *}$ \\
\hline Pain & 43 & 60 & McNemar's Test & $<0.0001^{* *}$ \\
\hline Temperature & 17 & 26 & & $0.012^{* *}$ \\
\hline
\end{tabular}

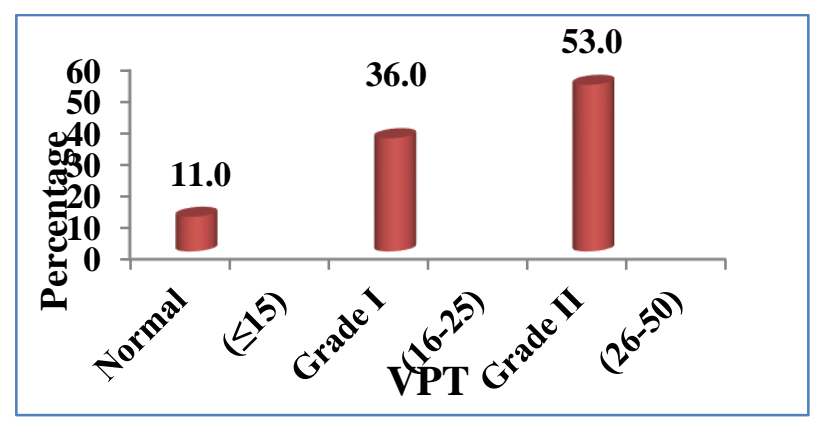

Figure 1: Distribution of patients based on severity of peripheral neuropathy.

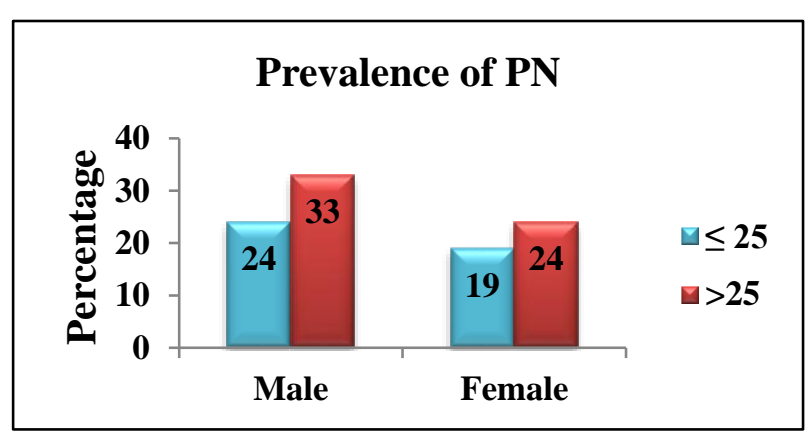

Figure 2: Distribution of patients according to prevalence of peripheral neuropathy. 


\section{DISCUSSION}

Several studies were carried out on knowledge, attitude and practice among diabetic foot patients. Current study shows that the knowledge, attitude and practice score of foot care among diabetes patients with foot at risk can be improved by patient counselling. In our study we can see a significant improvement in VPT value, foot examination status and other clinical parameters.

The present study disclosed that out of 100 patients, male patients $(57 \%)$ were more in number compared with female patients $(43 \%)$ and majority of the study participants lies between the age group of 60-69 years (45\%), which is similar to the study conducted by Sutariya et al. ${ }^{11}$ In our study majority of the study population (64\%) had a positive family history of DM (Table 2).

Among 100 patients, 35\% participants had diabetes for 10 years or less, $51 \%$ participants had diabetes for 11- 20 years, $11 \%$ had diabetes for 21-30 years and $3 \%$ participants suffering from DM for about 31-40 years (Table 2).

This study showed that about $11 \%$ of the study population had a VPT value of $15 \mathrm{~V}$ or less, $36 \%$ had a value of 16$25 \mathrm{~V}$ and $53 \%$ had a value of $26-50 \mathrm{~V}$ before providing counselling and after counselling a statistically significant improvement was seen i.e., about $19 \%$ had VPT $\leq 15 \mathrm{~V}$, $38 \%$ had VPT value $16-25 \mathrm{~V}$ and $43 \%$ of the participants VPT became 26-50V (Table 3).

The study assessed that majority of the participants $(65 \%)$ had poor knowledge, $29 \%$ had a satisfactory level of knowledge and only $6 \%$ of the population had a good knowledge before counselling was given and after counselling majority of patients had acquired a good knowledge (43\%). Most of the patients had a good attitude towards foot care before (71\%) and after (98\%) counselling. In the practice section, only $1 \%$ were in good practice, $12 \%$ had satisfactory practice and majority of the patients had poor practice $(87 \%)$ and after counselling the practice was improved by $25 \%$ with good practice, $62 \%$ with satisfactory practice and only $13 \%$ showed poor practice (Table 4).

The present study revealed, 65\% participants have poor knowledge about diabetic foot care which was very higher as compared to observation made by Sutariya et al in their study, that showed $28 \%$ participants with poor knowledge for the diabetic foot care. In this study, majority of the patients i.e., $87 \%$ had poor practice in contradiction to the observation of Sutariya et al which showed only $51 \%$ with poor practice for foot care. ${ }^{11}$

The study showed that majority of the patients $(92 \%)$ had dry skin before counselling and after counselling a very slight improvement was seen (84\%). About 63\% participants had fissures, 53\% had swelling, $27 \%$ had callus, $18 \%$ had interdigital mycosis and after counselling there was a significant improvement in fissures (18\%), swelling $(20 \%)$, callus $(11 \%)$, and in interdigital mycosis (5\%) (Table 7).

This study also revealed that majority of the patient can't perceive vibration, pain and temperature before counselling but after counselling there was a very slight improvement in all these parameters (Table 8).

From the study we found that before counselling, most of the patients were unaware of consequences of wearing Hawaii slippers. Such footwears are not a good protector from injuries because the foot is exposed to heat, dryness and injuries and there is a ridge like part that is commonly seen between the first and second toe and that may cause friction and injury. In this study, before counselling, only $27 \%$ of participants had dried their foot properly but after counselling it increased to $96 \%$. Most of the patients were not applying moisturising cream for preventing dryness but after counselling a majority of the patients applied it. Only a very few patients (5\%) were checking the foot properly and applying powder between the toes before counselling and after counselling there was an improvement in it (51\%).

The study showed that the peripheral neuropathy is more severe in patients with grade II VPT value (Figure 1).

The study also showed that the prevalence of peripheral neuropathy according to VPT value $(>25)$ is more in males than females (Figure 2).

From all the above results, we found a statistically significant improvement in KAP score (Table 5), VPT value (Table 6), Foot examination status (Table 7) and other clinical parameters (Table 8), showing that the counselling were very effective in improving the KAP Score, VPT value, Foot examination status and other clinical parameters.

\section{CONCLUSION}

The study revealed that majority of the study population had poor knowledge and practices regarding foot care. The deficiency in the knowledge may be due to poor communication between the doctors and the patients and also lack of counselling by the doctors and nurses due to their busy clinic schedule. It was found that when counselling was given, almost all patients acquired a good knowledge and followed a good foot care practice and there by showed an improvement in foot problems.

Poor knowledge and practice are the major reason for the amputation of limb as the people are unaware of their foot care. Thus, we concluded that by providing proper education regarding foot care, the foot complications can be decreased and there by the amputation rate can be reduced to an extent. 
Thus, patient education on the prevention of foot ulceration is imperative and should be incorporated into the routine care of patients with diabetes both in the hospital and in the community. Time must be allotted for communication, providing information and education during clinic sessions.

\section{ACKNOWLEDGEMENTS}

Authors would like to thank Almighty God for giving us the confidence and the presence of mind throughout this endeavour and completing this project without any problem. Our special thanks to Desalu O.O, who gave permission to use the scoring system.

Funding: No funding sources

Conflict of interest: None declared

Ethical approval: The study was approved by the Institutional Ethics Committee

\section{REFERENCES}

1. WHO. Diabetes mellitus. WHO int. 2019. Available at: https://www.who.int/mediacentre/factsheets/fs138/en /. Accessed 27 Feb 2019.

2. International Diabetes Federation-Idf.org. 2019. Available at: https://www.idf.org/. Accessed 27 Feb 2019.

3. Thomas N, Kapoor N, Velavan J, Vasan S. A Practical Guide to Diabetes Mellitus. $7^{\text {th }}$ ed. New Delhi: Jaypee The Health Sciences Publisher. 2018;13.

4. David Leslie R, Cecilia Lansang M, Coppack S, Kennedy L. Diabetes, 2014 ed. Manson publishing. 2015;208.
5. Kumar A, Pendsey S, Diabetic Foot Practical Guide for Prevention and Management. Diabetic foot. 2017;3.

6. Diabetic Foot Education Program India. Module IAssessment and Examination of Feet in Diabetics. Hansa MedCell.

7. Pendsey S. Contemporary Management of the Diabetic Foot: New Delhi, Jaypee Brothers Medical Publisher. 2014;56.

8. Younis BB, Shahid A, Arshad R, Khurshid S, Ahmad M, Yousaf H. Frequency of Foot Ulcers in People with Type 2 Diabetes, Presenting to Specialist Diabetes Clinic at a Tertiary Care Hospital, Lahore, Pakistan. BMC Endocrine Dis. 2018;18:1.

9. National Guidelines for Management of Diabetic Foot, 2 ed India: Diabetic Foot Society of India. 2017.

10. Desalu O, Salawu F, Jimoh A, Adekoya A, Busari O, Olokoba A. Diabetic foot care: Self-reported knowledge and practice among patients attending three tertiary hospital in Nigeria. Ghana Med J. 2011;45(2):60-5.

11. Sutariya P, Kharadi A. Knowledge and Practice of Foot Care among the patients of Diabetic Foot: A Hospital based cross-sectional study. Int Surg J. 2016:1850-5.

Cite this article as: Sivan S, Prasad S, Nandan P, Harikumar HK, Jacob LM, Thankam D. Knowledge, attitude and practice of foot care in diabetes patients with foot at risk attending diabetology department of a tertiary care hospital. Int J Basic Clin Pharmacol $2021 ; 10: 160-6$. 